\section{A) Check for updates}

Cite this: Food Funct., 2020, 11, 1489

\title{
Acrylamide in French fries prepared at primary school canteens
}

\author{
Marta Mesias, (D) * Cristina Delgado-Andrade, (D) Francisca Holgado (D) and \\ Francisco J. Morales (D)
}

\begin{abstract}
Children are one of the most exposed groups to dietary acrylamide with 'potato fried products' that account for up to half the total exposure to this contaminant. Acrylamide was measured in French fries prepared in 31 primary school canteens randomly recruited from different Spanish regions. The mean content was $329 \mu \mathrm{g} \mathrm{kg}^{-1}$ (from <20 to $4000 \mu \mathrm{g} \mathrm{kg}^{-1}$ ). French fries prepared from frozen par-fried potatoes reported a lower acrylamide content than those from fresh potatoes, 229 and $460 \mu \mathrm{g} \mathrm{kg}^{-1}$, respectively. Only $15.7 \%$ of samples were above the benchmark levels established by the EU Regulation 2017/ $2158\left(500 \mu \mathrm{g} \mathrm{kg}^{-1}\right)$. Significant differences were found according to the color of toasted $\left(2274 \mu \mathrm{g} \mathrm{kg}^{-1}\right)$, dark-golden $\left(463 \mathrm{\mu g} \mathrm{kg}^{-1}\right)$, golden $\left(134 \mathrm{\mu g} \mathrm{kg}^{-1}\right)$ and light-golden $\left(52 \mathrm{\mu g} \mathrm{kg}^{-1}\right)$ French fries. All the samples that were golden and light-golden showed acrylamide content below the threshold. The chromatic parameter $a^{*}$ was used as a rough classification of the French fries according to the benchmark level. Both educational initiatives intended for food operators and managerial-technical criteria that include the code of frying practices at public food service establishments should consider the golden color as the target for the end-point of frying. Acrylamide exposure will be reduced and, therefore, the risk linked to French fries consumption. This fact is especially relevant in establishments that prepare food for schoolchildren and would help to provide healthier diets, not only from a nutritional point of view but also from the reduction of chemical contaminants.
\end{abstract}

Received 23rd October 2019 Accepted 29th December 2019 DOI: $10.1039 /$ c9fo02482d rsc.li/food-function amide due to the high content of reducing sugars and asparagine in the fresh tuber and the intensity of the thermal treatment applied. In this regard, several recommendations focused on acrylamide mitigation in potato-based products have been described in Regulation $2017 / 2158,{ }^{4}$ in the guidance for industry on acrylamide in foods reported by the Food and Drug Administration ${ }^{5}$ and in the acrylamide toolbox compiled by FoodDrinkEurope. ${ }^{6}$ These recommendations include actions from the selection of suitable potato varieties to the control of potato storage, transport and processing, as well as educational resources to the end users about adequate cooking practices. Mitigation strategies are mainly directed to the industrial sector, where the measures are easier to apply due to well-controlled and more standardized processes. Thanks to these measures, acrylamide levels in industrial fried potatoes have decreased in the last several years, as corroborated by Mesias and Morales $^{7}$ in commercial potato crisps from the Spanish market. However, cooking practices in other scenarios such as public establishments, catering services, restaurants, or particular homes are not easily controllable. According to the EFSA, the total dietary exposure to acrylamide could be increased up to $80 \%$ depending on the home-cooking conditions of potato frying. ${ }^{1}$ Recently, our research group reported acrylamide levels ranging between $24-3641 \mu \mathrm{g} \mathrm{kg}{ }^{-1}$
Institute of Food Science, Technology and Nutrition (ICTAN-CSIC), Madrid, Spain

E-mail: mmesias@ictan.csic.es; Fax: +34 91549 3627; Tel: +34 915492300 
and $<20-1068 \mu \mathrm{g} \mathrm{kg}{ }^{-1}$ in French fries prepared in Spanish households and restaurants, respectively. ${ }^{8,9}$ The wide variability found in those studies points to the importance of considering the composition of the raw material and storage conditions before processing, ${ }^{4-6}$ in addition to the different culinary practices when calculating the dietary exposure to acrylamide, a fact established by the EFSA as well. ${ }^{1}$ In this respect, although the scientific research has explored to some extent the variability in acrylamide formation in French fries prepared in different sceneries, ${ }^{10,11}$ the information about public establishments that are not restaurants, such as school canteens, are rather limited ${ }^{12}$ and controversial. ${ }^{13}$

Children are one of the most exposed groups to acrylamide, in which the 'potato fried products' group represents up to half the total consume of this contaminant. ${ }^{1}$ It is relevant to highlight that in Spain, $36.4 \%$ of the students of early childhood education and $29.4 \%$ of primary school consume their main meal of the day at school. ${ }^{14}$ School canteens have a paramount role in their nutrition since children can consume up to $40 \%$ of their daily requirements at the primary school canteen. ${ }^{15}$ French fries preparation at school canteens has decreased in recent years due to the reduction of the consumption of fatty foods as a measure included in the NAOS strategy in Spain (Strategy for Nutrition, Physical Activity and Prevention of Obesity). ${ }^{16}$ However, these foods are consumed several times within the monthly menu of the schools, thus contributing to the acrylamide exposure of schoolchildren. The food operators from canteens have been instructed to promote a balanced diet among scholars. Nevertheless, mitigation practices are not extensively implemented to these public establishments, which may reduce the exposure to acrylamide across Spain. The aim of this investigation was to evaluate acrylamide levels in French fries prepared in primary school canteens and to identify the impact of cooking practices on the acrylamide content in these products.

\section{Materials and methods}

\subsection{Chemicals and reagents}

Potassium hexacyanoferrate(II) trihydrate (98\%, Carrez-I) and zinc acetate dihydrate ( $>99 \%$, Carrez-II) were obtained from Sigma (St Louis, USA). ${ }^{13} \mathrm{C}_{3}$-Labelled acrylamide (99\% isotopic purity) was obtained from Cambridge Isotope Laboratories (Andover, MA, USA). Formic acid (98\%), D(+)-glucose and methanol (99.5\%) were from Panreac (Barcelona, Spain). Deionized water was obtained from a Milli-Q Integral 5 water purification system (Millipore, Billerica, MA, USA). All other chemicals, solvents and reagents were of analytical grade.

\subsection{Study design}

Thirty-one randomly selected primary schools from three Spanish regions located in the center (Madrid), mid-east (Castilla La Mancha) and east of the country (Valencia) were recruited. In the school canteens, meals are daily prepared for primary school students aged between 6 and 12 years. Food operators prepared the French fries following their internal procedure. They did not receive instructions concerning the type of the potato (fresh or deep-frozen par-fried French fries), manipulation (peeling, cutting, soaking, blanching), frying appliance, frying temperature or frying oil used. They followed the internal canteen protocols for French fries frying and, in this way, a randomized and large scenario of the canteen practices was covered. Participants were unaware of the purpose of the research and not informed in detail about the acrylamide issue in order to avoid any influence during the experiment. They provided passive consent prior to completing the study, and did not receive any incentives for their participation. The study was conducted from May to June 2017.

\subsection{Sampling}

Participants received a 'kit of sampling' containing instructions for sampling according to the study design and containers properly coded to dispatch the samples. Food operators in each school were asked to collect a sample of unprocessed potatoes (fresh tuber or deep-frozen par-fried French fries) (ca. $100 \mathrm{~g})$, a sample of French fries ( $c a .100 \mathrm{~g}$ ) and a sample of frying oil ( $c a .25 \mathrm{~mL}$ ). Frying oil was collected just after the frying of the sample. Depending on the menu programmed for schoolchildren during the months of May and June 2017, 1 or 2 samples of potatoes per school were collected in this period, completing a total of 51 batch (51 samples of unprocessed potatoes, 51 samples of French fries and 51 samples of frying oil). Unprocessed potatoes, French fries and frying oil were frozen, placed in an airtight freezer bag and couriered to the lab. After reception, all the samples were stored at $-20^{\circ} \mathrm{C}$ until analysis.

\subsection{Questionnaire}

Within each school, food operators were asked to fill out a questionnaire in order to evaluate the culinary habits and specifically the potato frying practices, and any relevant aspect related to the formation of acrylamide in French fries. Questions were structured in check boxes with unique or multiple possible answers. The questionnaire was divided into five different themes, according to (i) potato characteristics, (ii) kitchen appliance and frying oil, (iii) pre-frying stage, (iv) frying stage, (v) and after-frying stage. School canteens agreed for the use of the data in the study.

\subsection{Characterization of unprocessed potatoes}

In this study, the term unprocessed potatoes aims to identify the raw material intended for frying as opposed to the final product. Canteens used fresh and deep-frozen par-fried potatoes. Once collected and dispatched to the lab, a batch of the unprocessed potatoes were freeze-dried and the moisture content was determined gravimetrically.

\subsection{Determination of reducing and total sugars}

The determination of the reducing sugar (glucose + fructose) content was performed in the freeze-dried unprocessed potatoes as described by Miller $^{17}$ with modifications from Mesias, 
Holgado, Márquez-Ruiz and Morales ${ }^{18}$ as adapted to a platereader. Total sugars (glucose + fructose + sucrose) content were obtained after acid hydrolysis from sucrose to glucose and fructose. Results were expressed as g glucose equivalents per $\mathrm{kg}$ of fresh sample. The limit of quantification (LOQ) calculated in the present study was set at $0.2 \mathrm{~g}$ glucose equivalents per $\mathrm{kg}$ sample. Analysis was done in duplicate.

\subsection{Asparagine determination by gas chromatography-flame ionization detection (GC-FID)}

The asparagine protocol was conducted according to Farkas and Toulouee ${ }^{19}$ with some minor modifications, as described in Mesias et al. ${ }^{8}$ Briefly, freeze-dried unprocessed potatoes (50 mg) were weighed into $50 \mathrm{~mL}$ screw top tubes. Then, $25 \mathrm{~mL}$ of acetonitrile $(25 \%, \mathrm{v} / \mathrm{v})$ were added into each tube, stirred for $30 \mathrm{~min}$ at room temperature and then centrifuged at $10000 \mathrm{~g}$ for $10 \mathrm{~min}$ at $4{ }^{\circ} \mathrm{C}$. Supernatant was collected in a $50 \mathrm{~mL}$ screw-top tube. Extraction was repeated with $25 \mathrm{~mL}$ of $25 \%$ acetonitrile. Supernatants were mixed and a $2 \mathrm{~mL}$ aliquot was transferred into a microcentrifuge tube and frozen overnight. After defrosting and centrifugation at $5000 \mathrm{~g}$ for $5 \mathrm{~min}$ at room temperature, samples were ready for derivatization and asparagine quantification using the commercially available EZ: faast amino acid kit (Phenomenex, Torrance, CA). $100 \mu \mathrm{L}$ of the extracted samples were transferred into sample preparation vials included in the EZ:faast GC-FID free amino acid kit. The derivatization of the potato sample extracts was performed according to the manual provided by the manufacturer and the asparagine was quantified using GC-FID (Agilent GC 7820A FID) equipped with an autosampler. An amino acid dedicated column (Zebron ZB-AAA capillary; $10 \mathrm{~m} \times 0.25 \mathrm{~mm}$ ) was used for the separation of amino acids. The oven was set to start at $110{ }^{\circ} \mathrm{C}$ and increased at $32{ }^{\circ} \mathrm{C}$ per minute up to $320{ }^{\circ} \mathrm{C}$. An aliquot of the derivatized sample $(1 \mu \mathrm{L})$ was injected at $250{ }^{\circ} \mathrm{C}$ in split mode $(15: 1)$. The FID detector was set to $320^{\circ} \mathrm{C}$ and the carrier helium gas flow rate was kept at $1.5 \mathrm{~mL} \mathrm{~min} \mathrm{~m}^{-1}$ during the run. An external calibration was carried out with an asparagine standard and results were corrected according to the recovery of norvaline, used as internal standard. Free asparagine content was expressed as $\mathrm{g} \mathrm{kg}^{-1}$ of fresh sample. Analysis was done in duplicate.

\subsection{Determination of CIELAB color}

Color measurements were made at room temperature using a HunterLab Spectrophotometer 150 CM-3500D colorimeter (Hunter Associates laboratory, Stamford, Connecticut, USA). Four independent measurements of $a^{*}$ (redness), $b^{*}$ (yellowness) and $L^{*}$ (lightness) parameters were carried out on different points on the surface of fried potatoes in order to take into account the non-homogeneous distribution of the color within the same batch of fried product or even in the same fried potato. $E$ index was calculated according to the following equation: $E=\left(L^{2}+a^{2}+b^{2}\right)^{1 / 2}$. The equipment was calibrated with a standard calibration white plate CR-A43 $\left(L^{*} / 93.80, a^{*} / 0.3156, b^{*} / 0.3319\right)$.

\subsection{Visual color sorting}

Three semi-trained panelists classified the fried samples after a visual inspection with a subjective division. Previously, the panelist established a consensus scale of darkening considering the French fry color chart by the Arvalis-Insitut du vegetal (France), and the standard color reference chart for frozen fried potatoes by the Munsell USDA (United States Department of Agriculture) guidelines. French fries were visually scored from the lightest to the brownest color, and after that, they were sorted as light-golden, golden, dark-golden or toasted.

\subsection{Acrylamide determination by liquid chromatography- electrospray ionization-tandem mass spectrometry}

Acrylamide was determined in fried samples as described by Mesias and Morales. ${ }^{7}$ The recovery rate of acrylamide spiked to the samples was between 90 and 106\%. The relative standard deviations (RSD) for the precision, repeatability and reproducibility of the analyses were calculated as $2.8 \%, 1.2 \%$ and $2.5 \%$, respectively. The limit of the quantitation was set at $20 \mu \mathrm{g}$ $\mathrm{kg}^{-1}$, complying with the performance criteria set by EU Regulation 2017/2158. The accuracy of the results was demonstrated for potato crisps and pre-cooked French fries in four proficiency tests launched by the Food Analysis Performance Assessment Scheme (FAPAS) program, yielding a $z$-score of -0.2 (Test 3071, Feb-March 2017) and -0.3 (Test 3080, FebMarch 2018), 0.0 (Test 3085, Sep-Oct 2018) and 0.3 (Test 3089, Feb-2019). Results of acrylamide were expressed as $\mu \mathrm{g} \mathrm{kg}{ }^{-1}$ of sample. Analysis was done in triplicate.

\subsection{Determination of polar compounds in oil}

Total polar compounds were measured in the frying oil by a hand-held device Testo 270 (Testo INC, New Jersey, USA), which is a rapid method based on the dielectric constant of the oil. Results were expressed as the percentage of total polar material ( $\mathrm{g}$ per $100 \mathrm{~g}$ oil). Analysis was done in triplicate.

\subsection{Statistical analysis}

Statistical analyses were performed using SPSS version 21.0 (SPSS Inc., Chicago, IL). Data are expressed as fresh weight. Student $t$-test and analysis of variance (one-way and two-way ANOVA) followed by the Fisher's test were used to identify the overall significance of differences between variables. The homogeneity of variances was determined with the Levene's test. Relationships between the different variables were evaluated by computing Spearman's linear correlation coefficients. All statistical parameters were evaluated at $p<0.05$ significance level.

\section{Results and discussion}

3.1. Description of the primary school canteens and culinary practices for frying potatoes

Thirty-one canteens from primary schools located in three Spanish regions completed the study, which included a frying test and an ad hoc questionnaire. Table 1 describes the charac- 
Table 1 Description of practices in the preparation of French fries in the different public school canteens expressed as a percentage of the participants

\begin{tabular}{|c|c|c|c|c|}
\hline \multicolumn{5}{|l|}{ Potato } \\
\hline \multirow[t]{2}{*}{ Potatoes } & Fresh & Par-fried & & \\
\hline & 43.1 & 56.9 & & \\
\hline \multirow[t]{2}{*}{ Storage } & Outdoor & Indoor & & \\
\hline & 0.0 & 100.0 & & \\
\hline \multirow[t]{2}{*}{ Cut } & Straight & Other & & \\
\hline & 60.8 & 30.8 & & \\
\hline \multirow{2}{*}{ Identification } & Procedence & Variety & None & Missing \\
\hline & 42.4 & 3.0 & 48.5 & 6.1 \\
\hline \multicolumn{5}{|c|}{ Frying oil and frying appliance } \\
\hline \multirow[t]{2}{*}{ Frying oil } & $\begin{array}{l}\text { Sunflower } \\
\text { oil }\end{array}$ & Other & & \\
\hline & 84.8 & 15.2 & & \\
\hline \multirow[t]{2}{*}{ Frying appliance } & Frying pan & $\begin{array}{l}\text { Electric } \\
\text { deep fryer }\end{array}$ & Both & \\
\hline & 9.1 & 84.8 & 6.1 & \\
\hline \multicolumn{5}{|l|}{ Pre-frying } \\
\hline \multirow[t]{2}{*}{ Washing $^{a}$} & Yes & No & & \\
\hline & 75.0 & 25.0 & & \\
\hline \multirow[t]{2}{*}{ Soaking $^{a}$} & Yes & No & & \\
\hline & 55.0 & 45.0 & & \\
\hline \multirow[t]{2}{*}{ Salting } & Before frying & After frying & Missing & \\
\hline & 6.5 & 38.7 & 54.8 & \\
\hline \multicolumn{5}{|l|}{ Frying } \\
\hline \multirow[t]{2}{*}{ Processing } & One stage & Other & & \\
\hline & 100.0 & 0.0 & & \\
\hline Temperature & yes & no & & \\
\hline control & 92.3 & 7.7 & & \\
\hline Potato/appliance & $<$ Half & Half & $>$ Half & Full \\
\hline surface & 24.2 & 60.6 & 9.1 & 6.1 \\
\hline \multicolumn{5}{|l|}{ After-frying } \\
\hline End-point & Color & Taste & Timer & Smell \\
\hline criteria & 72.7 & 9.1 & 12.1 & 6.1 \\
\hline Color & Light & Golden & Toasted & \\
\hline preference & 0.0 & 93.9 & 6.1 & \\
\hline \multirow[t]{2}{*}{ Oil removal } & Paper & Strainer & Both & None \\
\hline & 33.3 & 51.5 & 12.1 & 3.1 \\
\hline \multirow[t]{2}{*}{ Oil cleaning } & Strainer & Grater & Decantation & Not reuse \\
\hline & 48.5 & 15.2 & 9.0 & 27.3 \\
\hline \multirow[t]{2}{*}{$\begin{array}{l}\text { Oil replacement } \\
\text { criteria }\end{array}$} & Frying cycles & Dark color & $\begin{array}{l}\text { Strange } \\
\text { taste }\end{array}$ & Missing \\
\hline & 48.5 & 39.4 & 6.0 & 6.1 \\
\hline
\end{tabular}

teristics of the potatoes and the culinary practices for frying at each canteen. The survey showed that $56.9 \%$ of the participants used frozen potatoes (deep-frozen par-fried potatoes) and $43.1 \%$ used fresh potatoes that preferably were stored indoor at room temperature. French fries were mainly classic straight cut $(60.8 \%)$ and operators usually did not know the procedence or variety of the samples $(48.5 \%)$ or only knew the procedence $(42.4 \%)$. Most of the participants used electric deep fryers $(84.8 \%)$ of different capacities, and sunflower oil $(84.8 \%)$ as the frying oil. An amount of potatoes equivalent to half of the volume of the frying pan or the frying basket $(60.6 \%)$ (potato/appliance volume) were usually fried per batch. Most of the cooks washed the fresh potatoes before frying $(75.0 \%)$, whereas $55 \%$ applied an additional soaking step. Nearly half of the food handlers added salt to the potato $(45.2 \%)$, and mostly after frying $(38.7 \%)$. All the operators fried in one-step and most of them (92.3\%) controlled the tempera- ture of the process to some extent. Regarding after-frying habits, they considered the color as the main criterion that determines the end-point of frying $(72.7 \%)$ and preferred the golden color (93.9\%). Strainer (51.5\%) and absorbent paper (33.3\%) were mainly used to remove the excess oil from the fried potatoes. $48.5 \%$ of operators cleaned the oil by filtering it with a strainer and usually replaced the oil after a specific number of frying cycles (48.5\%) or when the oil got dark (39.4\%).

\subsection{Characterization of unprocessed potatoes, fried potatoes and frying oil}

Samples were analyzed for the content of acrylamide precursors and parameters that may play an important role in acrylamide formation. Determinations included the reducing sugars, total sugars, asparagine and moisture content in the unprocessed potatoes, polar compounds in the frying oil and color parameters (CIELab) in the French fries (Table 2).

The reducing sugar content in the unprocessed samples (fresh potatoes or par-fried potatoes) ranged from 0.53 to $31.15 \mathrm{~g} \mathrm{~kg}^{-1}$ (Table 2). The mean value was $5.63 \mathrm{~g} \mathrm{~kg}^{-1}$ and the median was set at $2.19 \mathrm{~g} \mathrm{~kg}^{-1} .29$ of the samples were frozen potatoes (par-fried potatoes) and 22 were fresh potatoes. Taking into account the type of samples, it is noteworthy to mention that the mean content of reducing sugars was $1.68 \pm$ $0.64 \mathrm{~g} \mathrm{~kg}^{-1}$ for frozen potatoes and $10.84 \pm 9.37 \mathrm{~g} \mathrm{~kg}^{-1}$ for fresh potatoes, with significant differences among both groups $(p<0.001)$. Regarding the total sugar content, a similar behavior was observed. The global content ranged from 1.33 to $34.50 \mathrm{~g} \mathrm{~kg}^{-1}$ and frozen samples showed a significantly lower mean content $\left(5.27 \mathrm{~g} \mathrm{~kg}^{-1}\right)$ as compared with fresh samples $\left(14.91 \mathrm{~g} \mathrm{~kg}^{-1}\right)$. The low levels in reducing sugars found in frozen potatoes were expected, since the industrial manufacturing of this food includes practices such as washing or blanching in hot water that reduce the levels of reducing sugars. ${ }^{20}$ In previous studies, Mesias et al. ${ }^{9}$ reported similar ranges of reducing sugars in frozen potatoes used for the preparation of French fries in Spanish restaurants. In those samples, even $49.6 \%$ showed a reducing sugar content lower than the limit of quantitation $\left(0.6 \mathrm{~g} \mathrm{~kg}^{-1}\right)$. On the other hand, data exhibited in fresh samples were close to those reported by Mesias et al. ${ }^{8}$ in potatoes intended for frying in Spanish homes. The acrylamide toolbox indicated a reducing sugar content lower than $4 \mathrm{~g} \mathrm{~kg}^{-1}$ for fresh potatoes intended for frying $^{6}$ and Regulation recommends special attention to the level of acrylamide when the reducing sugar content in potatoes is higher than $15 \mathrm{~g} \mathrm{~kg}^{-1}$. In the present study, 16 of 22 fresh potatoes $(73 \%)$ exhibited reducing sugar concentrations higher than $4 \mathrm{~g} \mathrm{~kg}^{-1}$ and 27\% (6 samples) exceeded $15 \mathrm{~g} \mathrm{~kg}^{-1}$. Sugars in potatoes depend on factors like variety, location, fertilization, storage and processing. ${ }^{21}$ Information concerning the potato traceability and providers were not supplied by the school canteens. However, seasonal potatoes are normally introduced in the Spanish market by mid-June or later; therefore, stored potatoes would be likely used in this study (MayJune). Fresh potatoes are usually stored from mid-October to 
Table 2 Descriptive analysis of the variables in unprocessed potatoes (sugars, asparagine, moisture), frying oil (polar compounds) and fried potatoes (color, acrylamide) in public school canteens

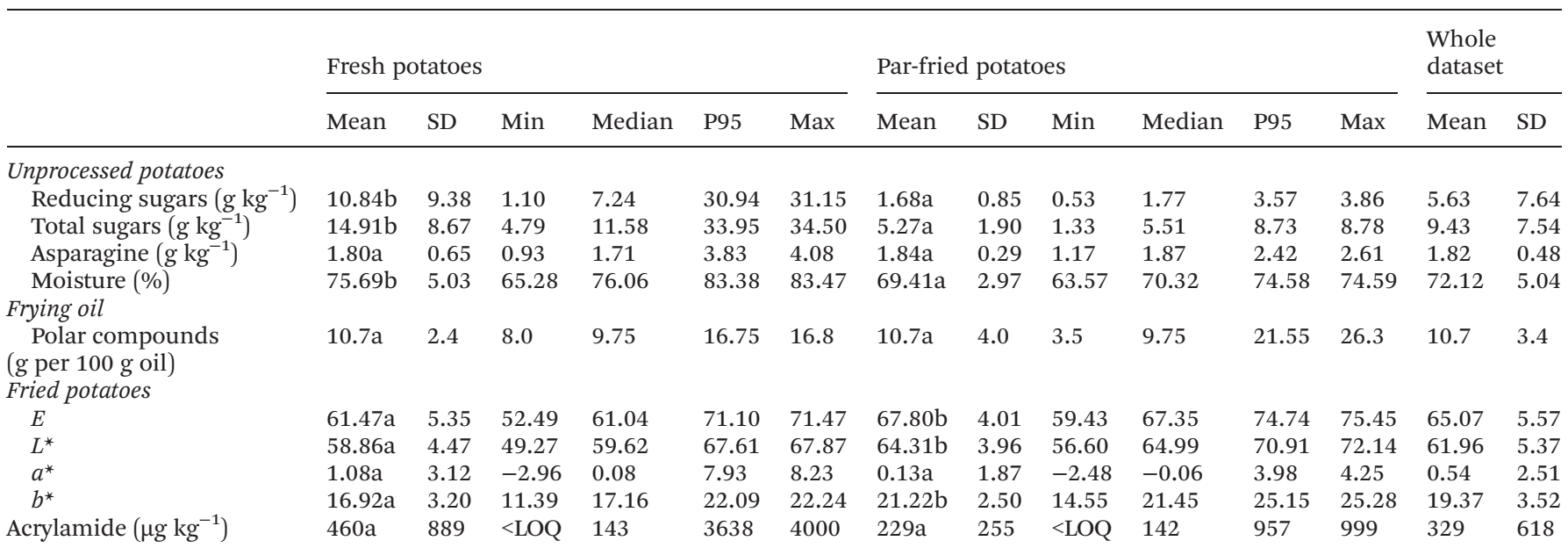

SD: standard deviation. Min: minimum. Max: maximum. LOQ: limit of quantitation. P95: $95^{\text {th }}$ percentile. Different letters mean significant differences between fresh and par-fried potatoes $(p<0.05)$.

April to make this product available all through the year. The low temperatures applied during storage promote the starch degradation and the increase of the sugar content, ${ }^{22}$ then providing more precursors for acrylamide formation during frying. ${ }^{6}$

Asparagine content ranged from 0.93 to $4.08 \mathrm{~g} \mathrm{~kg}^{-1}$, and $1.82 \mathrm{~g} \mathrm{~kg}^{-1}$ and $1.84 \mathrm{~g} \mathrm{~kg}^{-1}$ (Table 2) were the mean and median values, respectively, which are in line with previous studies. ${ }^{8,23,24}$ In this case, differences were not significant and both fresh and frozen samples showed similar contents (mean values 1.80 and $1.84 \mathrm{~g} \mathrm{~kg}^{-1}$, respectively). These results corroborate that pre-treatments applied to frozen par-fried potato strips intended for frying mainly affect the levels of reducing sugars but not the asparagine content of the sample, as described by Pedreschi, Kaack and Granby. ${ }^{25}$

Moisture content in the unprocessed potatoes ranged from 63.57 to $83.47 \%$, with a mean of $72.12 \%$ and a median of $71.43 \%$ (Table 2). The average moisture content in frozen parfried potatoes was $69.41 \%$, close to the $70 \%$ recommended in these kinds of samples ${ }^{26}$ whereas in fresh samples, a figure of $75.69 \%$ was found. Frozen and fresh potatoes displayed significant differences $(p<0.001)$, in line with previous studies. ${ }^{8,9}$

Polar compounds were measured in the frying oils, showing a range from 3.5 to $26.3 \mathrm{~g}$ per $100 \mathrm{~g}$ oil (Table 2). The mean value was 10.7 and the median was set at $9.8 \mathrm{~g}$ per $100 \mathrm{~g}$ oil. Only one sample exceeded the value of $25 \mathrm{~g}$ per $100 \mathrm{~g}$ oil, which is the limit established to control the quality of the frying oil after a number of frying cycles. ${ }^{27}$

French fries were characterized according to the CIELab color parameters, and a large range varied from lighter colors $\left(L^{*}=72.14\right)$ to darker colors $\left(L^{*}=49.27\right)$ (Table 2). Significant differences were observed among French fries coming from fresh or frozen par-fried potato strips for $b^{*}, L^{*}$ and $E$. These results were expected due to the different reducing sugar levels previously mentioned, since the higher sugar content promotes higher browning during the frying process. ${ }^{6}$ In this sense, significant correlations were found between the reducing sugars and parameters $b^{*}(\rho=-0.531, p<0.001), L^{*}(\rho=$ $-0.490, p<0.001)$, and $E(\rho=-0.524, p<0.001)$.

\subsection{Acrylamide content in French fries prepared in school canteens}

The acrylamide content showed a high variability, ranging from below the limit of quantitation $\left(20 \mu \mathrm{g} \mathrm{kg}^{-1}\right)$ to $4000 \mu \mathrm{g} \mathrm{kg}{ }^{-1}$ (Table 2, Fig. 1). The mean was $329 \pm 618 \mu \mathrm{g} \mathrm{kg}^{-1}$ and the median was $142 \mu \mathrm{g} \mathrm{kg}^{-1}$. Considering the type of potato intended to fry, the mean levels of acrylamide were $229 \mu \mathrm{g} \mathrm{kg}^{-1}$ in French fries prepared from frozen par-fried potatoes (gray bars in Fig. 1, range: <20-999) and $460 \mu \mathrm{g} \mathrm{kg}^{-1}$ from fresh samples (white bars in Fig. 1, range: $<20-4000$

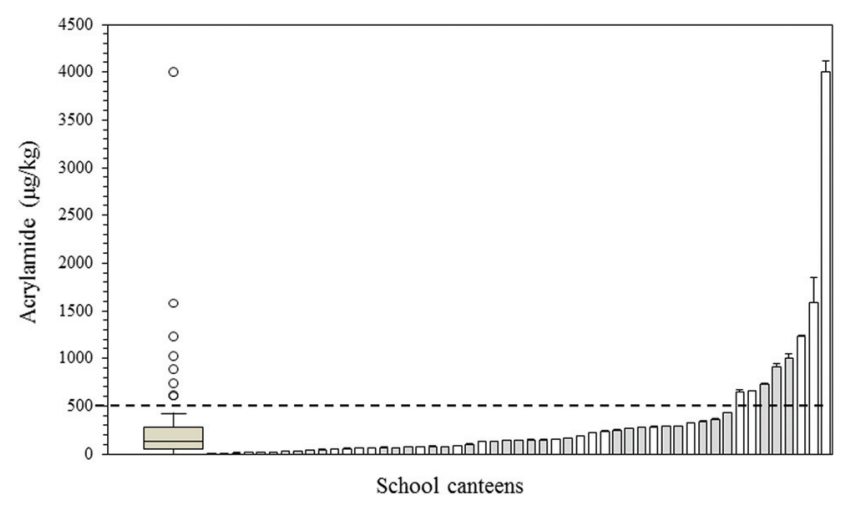

Fig. 1 Box-and-whisker plot and distribution graph for the acrylamide content $\left(\mu \mathrm{g} \mathrm{kg}^{-1}\right)$ in French fries prepared in school canteens $(n=51)$. Values are mean \pm SD. Dotted line indicates benchmark level for acrylamide in French fries. 
$\mu \mathrm{g} \mathrm{kg}^{-1}$ ). This variability reflects the diverse culinary practices in this randomized study. Likely, due to this variability within each group, differences in mean values were not significant $(p>0.05)$. Acrylamide concentrations were in the range reported in previous studies on French fries from frozen parfried potatoes prepared by Spanish restaurants $(<20-1068$ $\left.\mu \mathrm{g} \mathrm{kg}{ }^{-1}\right)^{9}$ and from fresh potatoes prepared in Spanish homes (24-3641 $\left.\mu \mathrm{g} \mathrm{kg}^{-1}\right){ }^{8}$ Similar levels have also been reported by other authors in this food. ${ }^{23,28}$ Regulation 2017/2158 established the reference of $500 \mu \mathrm{g} \mathrm{kg}{ }^{-1}$ as the benchmark level for French fries. ${ }^{4}$ In this study, $15.7 \%$ of the samples from the schools $(n=8)$ contained acrylamide concentrations above the reference value (Fig. 2). However, it has to be highlighted that all the samples exceeding the benchmark level were outliers of the normal distribution.
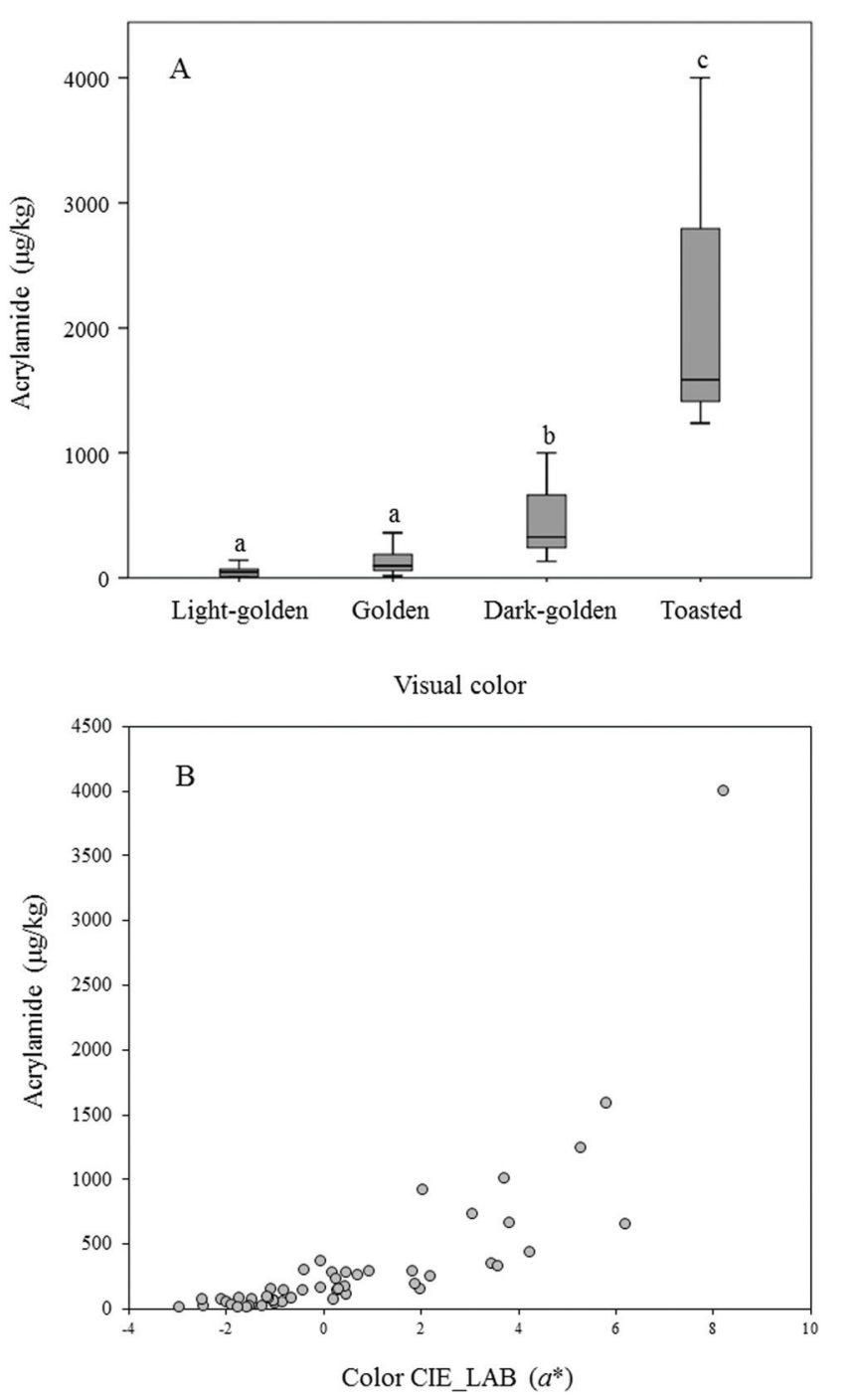

Fig. 2 Relationship between color and acrylamide content $\left(\mu \mathrm{g} \mathrm{kg}^{-1}\right)$ in French fries from school canteens. Box-and-whisker plot of acrylamide content according to the visual color (light-golden, golden, dark-golden and toasted) (A) and linear regression between acrylamide content and color parameter $a^{*}(B)$.
Considering that the menus in the school canteens include a frequency of 1-2 French fries portions per month and estimating that $95 \mathrm{~g}$ of the mean French fries portion is consumed by the childhood population, ${ }^{29}$ then the consumption of French fries could account for 3.2-6.3 $\mathrm{g}$ day $^{-1}$. Taking the mean value for acrylamide in French fries $\left(329 \mu \mathrm{g} \mathrm{kg}^{-1}\right)$, the daily dietary acrylamide exposure would range from 1.04 to $2.08 \mu \mathrm{g}$ per student per day. The contribution of acrylamide intake from French fries in primary school canteens would range between $0.03-0.07 \mu \mathrm{g}$ per $\mathrm{kg}$ bw per day for a 6-9 years old student (mean body weight $30 \mathrm{~kg})^{30}$ and between 0.02-0.05 $\mu \mathrm{g}$ per $\mathrm{kg}$ bw per day for those aged 10-11 (mean body weight $45 \mathrm{~kg}$ ). ${ }^{31}$ This exposure is much lower than data reported in Italian schoolchildren consuming a canteen menu. ${ }^{13}$

\subsection{Factors affecting acrylamide content in French fries}

Levels of acrylamide in French fries are a consequence of the characteristics of the potatoes intended for frying and the frying conditions, but also of the food operators regarding their culinary habits and the final point of frying. The influence of frying oil, kitchen appliance and pre-frying stage practices, considered individually or in combination, were evaluated and not significant effects were observed. Most food operators used sunflower oil (84.8\%) and an electric deep fryer $(84.8 \%)$, which makes it difficult to establish a possible influence of these parameters. Regarding washing and soaking, it must be considered that these practices are only referred to fresh tubers ( $43 \%$ of the total samples), leading again to a partial evaluation of the relationship with acrylamide formation (Table 1).

The strength and direction of the relationship among the different quantitative parameters and the acrylamide content has been investigated by using bivariate correlations analysis. Results were expressed as Spearman correlation coefficients following the procedure for non-parametric variables (Table 3). Correlations among precursors (reducing sugars and aspara-

Table 3 Bivariate correlations between the quantitative variables in unprocessed potatoes, frying oil and French fries, and the formation of acrylamide. Spearman's correlation coefficient $(\rho)$ and level of significance ( $p$ value)

\begin{tabular}{lcl}
\hline & Rho Spearman $(\rho)$ & $p$ Value \\
\hline Unprocessed potatoes & & \\
Reducing sugars $\left(\mathrm{g} \mathrm{kg}^{-1}\right)$ & 0.128 & 0.371 \\
Total sugars $\left(\mathrm{g} \mathrm{kg}^{-1}\right)$ & -0.1305 & 0.2051 \\
Asparagine $\left(\mathrm{g} \mathrm{kg}^{-1}\right)$ & 0.046 & 0.750 \\
Moisture $(\%)$ & -0.179 & 0.209 \\
Frying oil & & \\
Polar compounds (g per 100 g oil) & 0.072 & 0.618 \\
French fries & & \\
$E$ & -0.302 & $0.031^{*}$ \\
$L^{*}$ & -0.406 & $0.003^{* *}$ \\
$a^{*}$ & 0.884 & $0.000^{* * *}$ \\
$b^{*}$ & 0.252 & 0.075
\end{tabular}

Significant values are expressed as ${ }^{*}(p<0.05),{ }^{*}(p<0.01),{ }^{* *}(p<$ $0.001)$. 
gine) in unprocessed potatoes and acrylamide content in French fries were not significant whether all the samples were considered together or even if they were classified as fresh or frozen par-fried potatoes. It is known that reducing sugars are the limiting factor of the formation of acrylamide in potato products. ${ }^{32,33}$ A direct relationship between the reducing sugar content in fresh tubers and acrylamide formation in French fries has been reported when tubers are processed, sliced and fried under controlled conditions. ${ }^{18,34}$ However, this correlation is missing when frying under random conditions. In this sense, although the sugars may contribute to acrylamide formation in French fries, the different frying practices add new sources of variability, thus increasing the uncertainty of the study. ${ }^{8}$

Moisture content and polar compounds in the frying oil were not significantly correlated to that of acrylamide either (Table 3). In contrast, a significant relationship between the color in fried potatoes and acrylamide levels was observed. According to the visual appearance, samples were classified as light-golden, golden, dark-golden and toasted. As expected, the most browned French fries (toasted) contained significantly higher levels of acrylamide (mean: $2274 \mu \mathrm{g} \mathrm{kg}{ }^{-1}$ ), as compared with dark-golden (mean: $463 \mu \mathrm{g} \mathrm{kg}{ }^{-1}$ ) and golden color (mean: $134 \mu \mathrm{g} \mathrm{kg}{ }^{-1}$ ) (Fig. 2A). All the samples in the light-golden and golden groups presented acrylamide concentrations lower than the benchmark level set by the European Regulation, without significant differences among these groups. In the rest of the French fries, the percentages of samples with acrylamide content higher than $500 \mu \mathrm{g} \mathrm{kg}^{-1}$ were $38 \%$ in dark-golden and $100 \%$ in toasted French fry groups. This trend was corroborated by a significant correlation between the CIElab parameters and acrylamide concentrations (Table 3). Acrylamide was negatively correlated with $L^{*}(\rho=$ -0.406; $p=0.003)$ and the $E$-index $(\rho=-0.302 ; p=0.031)$, which indicates that the browning and lower luminosity in fried potatoes involves greater amounts of the contaminant. The correlation with $b^{*}$ did not become significant, however a stronger relationship was exhibited by the parameter $a^{*}(\rho=$ $0.884 ; p<0.001$ ) (Table 3, Fig. 2B). These results are in agreement with the literature, since previous studies have identified the chromatic parameter $a^{*}$ as a useful predictor of the acrylamide formation in fried potatoes. ${ }^{8,9,35-38}$ This variable was able to discriminate between the four types of French fries according to the visual color. The statistical comparison of this variable in the French fry samples grouped by each visual color category led to significant differences (Fig. 3A). In addition, parameter $a^{*}$ exhibited a trend to differentiate samples grouped according to the acrylamide levels using the benchmark level as the threshold $\left(500 \mu \mathrm{g} \mathrm{kg}^{-1}\right)$, with differences that were almost significant $(p=0.055)$ (Fig. 3B). The lack of homogeneity in the potato pieces (i.e. thickness) and the final moisture content in the French fries contributed to increasing the variability of the process and, in consequence, a lower strength in the statistical descriptor was observed.

The rate of acrylamide formation increases at the end of the frying and therefore the end-point is considered a key factor. ${ }^{39}$ In order to prevent the formation of the contaminant, the end-
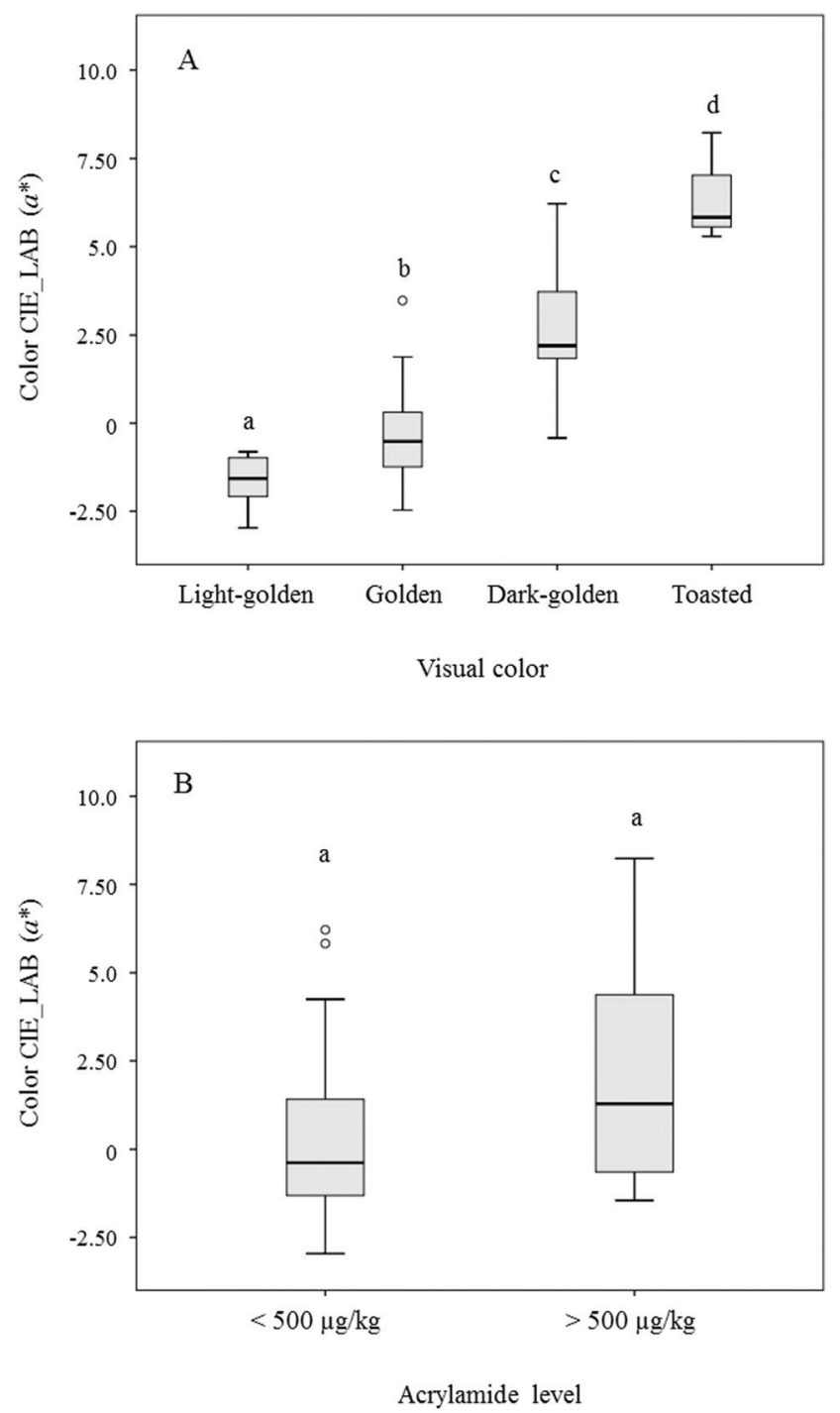

Fig. 3 Box-and-whisker plot of color parameter $a^{*}$ according to the visual color (light-golden, golden, dark-golden and toasted) (A) and to the acrylamide levels using the benchmark level as the threshold $\left(500 \mu \mathrm{g} \mathrm{kg}^{-1}\right)$ (B) of French fries from school canteens.

point of frying may be controlled to avoid excessive browning. In this respect, educational initiatives aimed at food operators that focus on good frying habits, such as the ideal golden color in fried potatoes, should be proposed to reduce the acrylamide exposure and, therefore, the risk linked to the French fries' consumption. This statement agrees with Sanny et al. ${ }^{28,40}$ that evaluated the effect of frying instructions for food handlers on acrylamide formation in French fries prepared in food service establishments and concluded that the training of food handlers is an effective strategy to reduce acrylamide formation. In the present study, most operators considered the color as the main criterion that determines the end-point of frying potatoes and identified the golden color as the target (Table 1). However, the high acrylamide levels found in some of the samples suggest that these criteria are not enough since the perception of color is subjective. 


\section{Conclusions}

The present study confirms that the acrylamide content in most French fries processed in primary school canteens $(84.3 \%)$ was below the benchmark levels established by Regulation 2017/2158. Despite these results, the use of color guides and/or chemometric devices based on color parameters, as proposed in the acrylamide Regulation, may be recommended in food service establishments for monitoring acrylamide levels and reducing exposure to this contaminant. This fact turns out to be relevant in public establishments, especially in those preparing foods intended for schoolchildren. In this regard, the elimination of dark golden and toasted fries before serving could be a valuable action in avoiding overexposure to acrylamide. In the last several years, school policies have been targeted to improve diet, reducing the consumption of foods rich in sugar and fat and providing balanced lunches for students. ${ }^{41}$ Together with this initiative, the application of measures to reduce the exposure to acrylamide in foods would help to provide healthier diets, not only from a nutritional but also a toxicological point of view. The findings provide valuable information for policy makers and public health bodies to enhance implementation and monitoring strategies for acrylamide in school canteens, and also to food operators reviewing the code of practice in frying potatoes.

\section{Conflicts of interest}

The authors declare that they have no conflict of interest.

\section{Acknowledgements}

This research was partly funded by the Ministerio de Economia y Competitividad (Spain) under the project SAFEFRYING (AGL2015-46234-R; MINECO/FEDER, UE) and by the Ministerio de Ciencia, Innovacion y Universidades (Spain) under the project ACRINTAKE (RTI2018-094402-B-I00, MCIU/ AEI/FEDER, UE). Authors thank Ms I. Alvarez and Ms B. Díaz their technical assistance, school canteens their participation, and to the staff of the General Directorate for Public Health of the Autonomous Community Castilla-La Mancha (Spain) through its Food Health Service for the sampling and the coordination among the primary schools.

\section{Notes and references}

1 EFSA (European Food Safety Authority), Scientific opinion on acrylamide in food, EFSA J., 2015, 13, 4104 https://efsa. onlinelibrary.wiley.com/doi/pdf/10.2903/j.efsa.2015.4104 (accessed May 2019).

2 IARC (International Agency for Research on Cancer), Some industrial chemicals, in IARC Monographs on the evaluation for carcinogenic risk of chemicals to, humans, IARC, Lyon,
1994, vol. 60, pp. 435-453. https://publications.iarc.fr/133 4104 (accessed May 2019).

3 R. H. Stadler, I. Blank, N. Varga, F. Robert, J. Hau, P. A. Guy, M. C. Robert and S. Riediker, Acrylamide from Maillard reaction products, Nature, 2002, 419, 449450.

4 EC (European Commission), Commission Regulation (EU) 2017/2158 of 20 November 2017 establishing mitigation measures and benchmark levels for the reduction of the presence of acrylamide in food, Off. J. Eur. Union, 2017, L304, 2444 https://eur-ex.europa.eu/legalcontent/EN/TXT/HTML/?uri= CELEX:32017R2158\&from=EN4104 (accessed May 2019).

5 FDA (Food and Drug Administration), Guidance for Industry Acrylamide in Foods, 2016, https:/www.fda.gov/media/ 87150/download (accessed August 2019).

6 FoodDrinkEurope (FDE), 2019, https://www.fooddrinkeurope.eu/uploads/publications_documents/FoodDrinkEurope_ Acrylamide_Toolbox_2019.pdf (accessed July 2019).

7 M. Mesias and F. J. Morales, Acrylamide in commercial potato crisps from Spanish market: Trends from 2004 to 2014 and assessment of the dietary exposure, Food Chem. Toxicol., 2015, 81, 104-110, DOI: 10.1016/j.fct.2015.03.031.

8 M. Mesias, C. Delgado-Andrade, F. Holgado and F. J. Morales, Acrylamide content in French fries prepared in households: A pilot study in Spanish homes, Food Chem., 2018, 260, 44-52, DOI: 10.1016/j.foodchem.2018.03.140.

9 M. Mesias, C. Delgado-Andrade, F. Holgado and F. J. Morales, Acrylamide content in French fries prepared in food service establishments, LWT - Food Sci. Technol., 2019, 100, 83-91, DOI: 10.1016/j.lwt.2018.10.050.

10 F. Mestdagh, C. Lachat, K. Baert, E. Moons, P. Kolsteren, C. Van Peteghem and B. De Meulenaer, Importance of a canteen lunch on the dietary intake of acrylamide, Mol. Nutr. Food Res., 2007, 51, 509-516, DOI: 10.1002/mnfr.200600253.

11 L. Normandin, M. Bouchard, P. Ayotte, C. Blanchet, A. Becalski, Y. Bonvalot, D. Phaneuf, C. Lapointe, M. Gagné and M. Courteau, Dietary exposure to acrylamide in adolescents from a Canadian urban center, Food Chem. Toxicol., 2013, 57, 75-83, DOI: 10.1016/j.fct.2013.03.005.

12 M. M. El-Tawila, A. M. Al-Ansari, A. A. Alrasheedi and A. A. Neamatallah, Dietary exposure to acrylamide from cafeteria foods in Jeddah schools and associated risk assessment, J. Sci. Food Agric., 2017, 97, 4494-4500, DOI: 10.1002/jsfa.8314.

13 R. Branciari, R. Roila, D. Ranucci, M. S. Altissimi, M. L. Mercuri and N. M. Haouet, Estimation of acrylamide exposure in Italian schoolchildren consuming a canteen menu: health concern in three age groups, Int. J. Food Sci. Nutr., 2020, 71, 122-131, DOI: 10.1080/09637486.2019.1624692.

14 V. Villadiego and N. Castro, Radiografía del sector de la restauración escolar, in Los comedores escolares en España. Del diagnóstico a las propuestas de mejora, Del campo al Cole, Madrid, Spain, 2018, pp. 10-26, https://ciudadesagroecologicas.eu/wp-content/uploads/2018/09/InformeComedores-Escolares.pdf (accessed September 2019).

15 A. C. Bell and B. A. Swinburn, What are the key food groups to target for preventing obesity and improving 
nutrition in schools?, Eur. J. Clin. Nutr., 2004, 58, 258-263, DOI: $10.1038 /$ sj.ejcn.1601775.

16 Agencia Española de Seguridad Alimentaria, Estrategia para la nutrición, actividad física y prevención de la obesidad (NAOS). Invertir la tendencia de la obesidad, Agencia Española de Seguridad Alimentaria, Madrid, Spain, 2015.

17 G. L. Miller, Use of dinitrosalicylic acid reagent for determination of reducing sugars, Anal. Chem., 1959, 31, 426-428, DOI: 10.1021/ac60147a030.

18 M. Mesias, F. Holgado, G. Márquez-Ruiz and F. J. Morales, Impact of the characteristics of fresh potatoes available inretail on exposure to acrylamide: Case study for French fries, Food Control, 2017, 73, 1407-1414, DOI: 10.1016/j. foodcont.2016.11.005.

19 T. Farkas and J. Toulouee, Asparagine analysis in food products, $L C \cdot G C$ Eur., 2003, 21, 14-16.

20 F. Pedreschi, Fried and Dehydrated Potato Products, in Advances in Potato Chemistry and Technology, ed. S. Jaspreet and K. Lovedeep, Academic Press, San Diego, USA, 2009, pp. 319-337.

21 C. Rosen, N. Sun, N. Olsen, M. Thornton, M. Pavek, L. Knowles and N. R. Knowles, Impact of Agronomic and Storage Practices on Acrylamide in Processed Potatoes, Am. J. Potato Res., 2018, 95, 319-327, DOI: 10.1007/s12230018-9659-8.

22 T. De Wilde, B. De Meulenaer, F. Mestdagh, Y. Govaert, S. Vandeburie, W. Ooghe, S. Fraselle, K. Demeulemeester, C. Van Peteghem, A. Calus, J. M. Degroodt and R. Verhé, Influence of Storage Practices on Acrylamide Formation during Potato Frying, J. Agric. Food Chem., 2005, 53, 65506557, DOI: $10.1021 /$ jf050650s.

23 J. S. Elmore, G. Koutsidis, A. T. Dodson, D. S. Mottram and B. L. Wedzicha, Measurement of acrylamide and its precursors in potato, wheat, and rye model systems, J. Agric. Food Chem., 2005, 53, 1286-1293, DOI: 10.1021/jf048557b.

24 V. Vivanti, E. Finotti and M. Friedman, Level of acrylamide precursors asparagine, fructose, glucose, and sucrose in potatoes sold at retail in Italy and in the United States, J. Food Sci., 2006, 71, C81-C85, DOI: 10.1111/j.13652621.2006.tb08886.x.

25 F. Pedreschi, K. Kaack and K. Granby, Reduction of acrylamide formation in potato slices during frying, LWT - Food Sci. Technol., 2004, 37, 679-685, DOI: 10.1016/ j.lwt.2004.03.001.

26 E. Bradshaw and G. Ramsay, Potato origin and production, in Advances in potato chemistry and technology, ed. S. Jaspreet and K. Lovedeep, Academic Press, San Diego, USA, 2017, pp. 1-26.

27 M. C. Dobarganes and G. Márquez-Ruiz, Regulation of used frying fats and validity of quick tests for discarding the fats, Grasas Aceites, 1998, 49, 331-335, DOI: 10.3989/ gya.1998.v49.i3-4.735.

28 M. Sanny, S. Jinap, E. J. Bakker, M. A. J. S. van Boekel and P. A. Luning, Possible causes of variation in acrylamide concentration in French fries prepared in food service establishments: An observational study, Food Chem., 2012, 132, 134-143, DOI: 10.1016/j.foodchem.2011.10.044.

29 Agencia Española de Seguridad Alimentaria, Documento de Consenso sobre la alimentación en los Centros Educativos, Agencia Española de Seguridad Alimentaria, Madrid, Spain, 2010.

30 Agencia Española de Seguridad Alimentaria, Estudio Aladino. Estudio de vigilancia del crecimiento, alimentación, actividad física, desarrollo infantil y obesidad en España, Agencia Española de Seguridad Alimentaria, Madrid, Spain, 2015.

31 A. Gálvez Casas, P. L. Rodríguez García, A. Rosa Guillamón, E. García-Cantó, J. J. Pérez Soto, M. L. Tárraga Marcos and P. J. Tárraga López, Nivel de condición física y su relación con el estatus de peso corporal en escolares, Nutr. Hosp., 2015, 31, 393-400.

32 A. Becalski, B. P. Y. Lau, D. Lewis, S. W. Seaman, S. Hayward, M. Sahagian, M. Ramesh and Y. Leclerc, Acrylamide in French Fries: Influence of Free Amino Acids and Sugars, J. Agric. Food Chem., 2004, 52, 3801-3806, DOI: 10.1021/jf0349376.

33 J. S. E. Williams, Influence of variety and processing conditions on acrylamide levels in fried potato crisps, Food Chem., 2005, 90, 875-881, DOI: 10.1016/j.foodchem.2004.05.050.

34 B. Mattäus and N. U. Haase, Acrylamide. Still a matter of concern for fried potato food?, Eur. J. Lipid Sci. Technol., 2014, 116, 675-687 http://onlinelibrary.wiley.com/doi/ 10.1002/ejlt.v116.6/issuetoc.

35 F. Pedreschi and P. Moyano, Effect of pre-drying on texture and oil uptake of potato chips, LWT - Food Sci. Technol., 2005, 38, 599-604, DOI: 10.1016/j.lwt.2004.08.008.

36 F. Pedreschi, K. Kaack and K. Granby, Acrylamide content and color development in fried potato strips, Food Res. Int., 2006, 39, 40-46, DOI: 10.1016/j.foodres.2005.06.001.

37 F. Pedreschi, K. Kaack, K. Granby and E. Troncoso, Acrylamide reduction under different pre-treatments in French fries, J. Food Eng., 2007, 79, 1287-1294, DOI: 10.1016/j.jfoodeng.2006.04.014.

38 V. Gökmen, H. Z. Senyuva, B. Dülek and A. E. Çetin, Computer vision-based image analysis for the estimation of acrylamide concentrations of potato chips and french fries, Food Chem., 2007, 101, 791-798, DOI: 10.1016/j. foodchem.2006.02.034.

39 M. Palermo, V. Gokmen, B. De Meulenaer, Z. Ciesarova, Y. Zhang, F. Pedreschi and V. Fogliano, Acrylamide mitigation strategies: Critical appraisal of the FoodDrinkEurope toolbox, Food Funct., 2016, 7, 2516-2525, DOI: 10.1039/c5fo00655d.

40 M. Sanny, P. A. Luning, S. Jinap, E. J. Bakker and M. A. J. S. van Boekel, Effect of Frying Instructions for Food Handlers on Acrylamide Concentration in French Fries: An Explorative Study, J. Food Prot., 2016, 76, 462-472, DOI: 10.4315/0362-028X.JFP-12-049.

41 T. K. Behrens, M. L. Liebert, H. J. Peterson, H. J. Smith, J. T. Sutliffe, A. Day and J. Mack, Changes in School Food Preparation Methods Result in Healthier Cafeteria Lunches in Elementary Schools, Am. J. Prev. Med., 2018, 54, S139S144, DOI: 10.1016/j.amepre.2018.01.008. 